\title{
Excluídos e invisíveis
}

Maria Ignês Carlos Magno

Doutora em Ciências da Comunicação pela ECA/USP.

Professora do curso de Pedagogia do Centro Universitário Salesiano

de São Paulo e da Universidade Anhembi Morumbi.

E-mail: unsig@globo.com

[...] Essas expressões pretendem ressaltar a existência de uma parte da vida social que escapa à ordem da racionalidade instrumental, não se deixa capturar pelo finalismo nem reduzir a uma simples lógica da dominação. A duplicidade, a astúcia e o querer-viver exprimem-se através de uma multiplicidade de rituais, de situações, de gestuais e de experiências que delimitam um espaço de liberdade ${ }^{1}$.

Em todo o mundo são cerca de 171 milhões de crianças que são obrigadas a trabalhar em condições perigosas e com maquinaria pouco segura, em fábrica, em minas e na agricultura².

Os filmes escolhidos são de naturezas diferentes. O primeiro é o documentário narrativo Camelos Também Choram, que trata da vida dos nômades do deserto de Gobi na Mongólia; o segundo, Crianças Invisíveis, divide-se em sete curtas de vários países que têm como temática a dura realidade de personagens infantis. No entanto, ambos os filmes possuem dois aspectos comuns: a exclusão - ou porque a diferença nos fere, ou porque veda os mesmos olhos - e a idéia de invisível, ou o que se pode tornar visível por meio de um exercício muito especial, qual seja, a percepção do que está além do dizível e do visível; marcas, gestos e ritos que só podem ser percebidos em pequenas manifestações da vida e do cotidiano, seja de tribos, grupos ou pessoas. Manifestações estas dificilmente controladas pela racionalidade contemporânea, porque estão situadas numa outra esfera das relações humanas e culturais.

Pensando nesses dois aspectos, proponho para este número da revista um duplo exercício do olhar: discutir o que está dado a ser visto e o que pode ser descoberto.

\section{FICHA TÉCNICA}

Camelos Também Choram (Die Geschichte vom Weinenden Kamel) ${ }^{3}$

Direção - Byambasuren Davaa e Luigi Falorni

Roteiro - Byambasuren Davaa e Luigi Falorni

Música - Marcel Leniz, Marc Riedinger e Choigiw Sangidorj

Fotografia - Luigi Falorni

1. MAFFESOLI, Michel. O mistério da conjunção: ensaios sobre comunicação, corpo e socialidade. Porto Alegre: Sulina, 2005. p. 83.

2. <http://www.adital. com $\mathrm{br} / \mathrm{site} /$ noticia.asp?lang $=$ PT\&cod=20458>.

3. Crédito das fotos das filmagens de Camelos Também Choram: <http:// www.thinkfilmcompany. com/weepingcamel/downloads/crew.jpg>. 
Lançamento - Alemanha e Mongólia

Gênero - Documentário

Ano - 2004

Duração - 78 min

No deserto de Gobi, situado ao sul da Mongólia, a época da primavera é tempo da cria de camelos, um importante animal para quatro gerações de criadores de ovelhas que vivem numa pequena aldeia da região, já que serve de meio de transporte aos nômades e é provedor de lã.

Uma família nômade de sheperds, os habitantes locais, trabalha no nascimento do seu rebanho de camelos. Um dos animais tem um

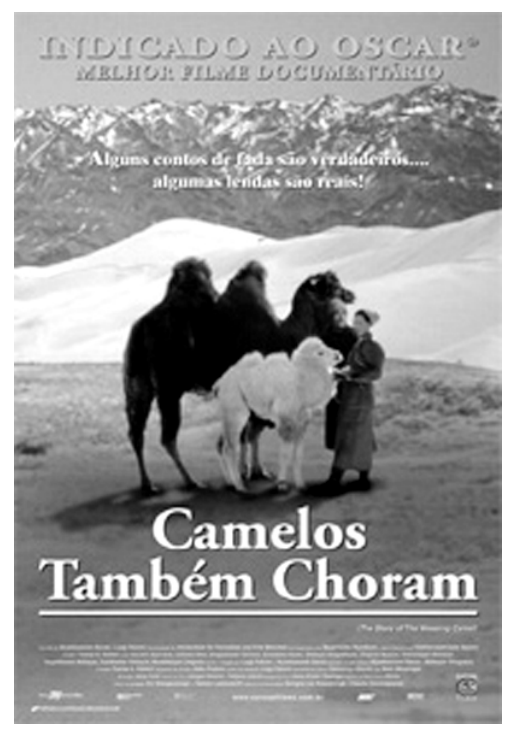
parto doloroso. Só depois de muito esforço nasce um pequeno camelo branco, muito raro. O recém-nascido é recusado pela mãe, que não lhe dá atenção nem leite. Quando a esperança de que o camelo branco conseguirá sobreviver começa a acabar, os mais velhos da família enviam seus dois garotos em uma viagem pelo deserto até o local onde vive um músico capaz de salvar a vida do pequeno camelo.

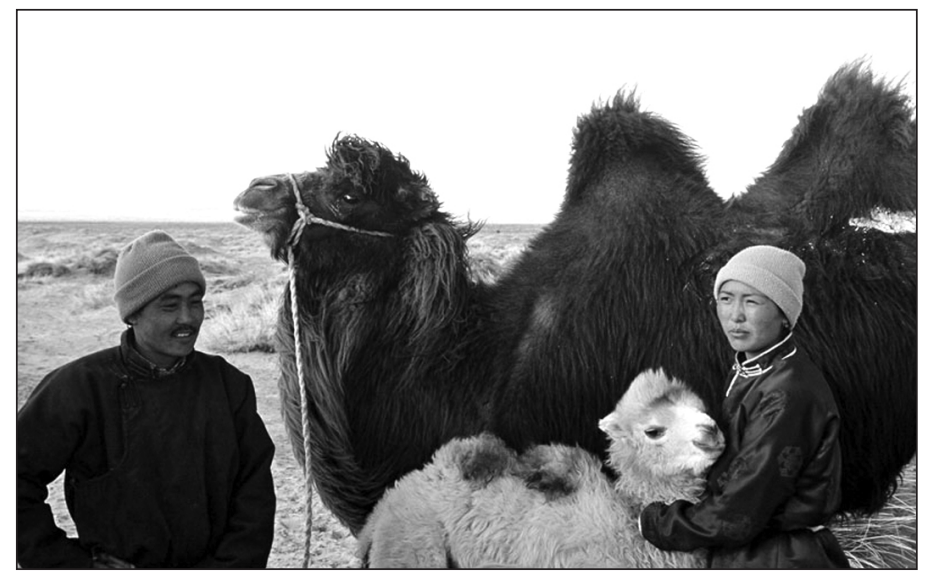

\section{FICHA TÉCNICA}

Crianças Invisiveis (All the Invisible Children)

Direção - Mehdi Charef (argelino), Emir Kusturica (iugoslavo), Spike Lee (americano), Kátia Lund (brasileira), Jordan e Ridley Scott (ingleses), Stefano Veneruso (italiano) e John Woo (chinês)

Roteiros - Mehdi Charef, Diogo de Silva, Stribor Kusturica, Spike Lee, Kátia Lund, Jordan Scott, Stefano Veneruso e Qiang Li.

Música - Terence Blanchard, Ramin Djawid e Hai Lin. 
Fotografia - Philippe Brelot, Cliff Charles, Changwei Gu, Toca Seabra, Vittorio Storaro, Jim Whitaker e Nianping.

Gênero - Drama

Lançamento - Itália

Ano - 2005

Duração - 116 min

Crianças Invisíveis reúne sete curtas protagonizados por crianças de várias regiões do planeta. Cada um mostra diferentes situações e problemas vividos por elas, seja em São Paulo coletando sucata nas ruas, seja roubando para viver em Nápoles, ou no reformatório de Sérvia e Montenegro. Os filmes apresentam

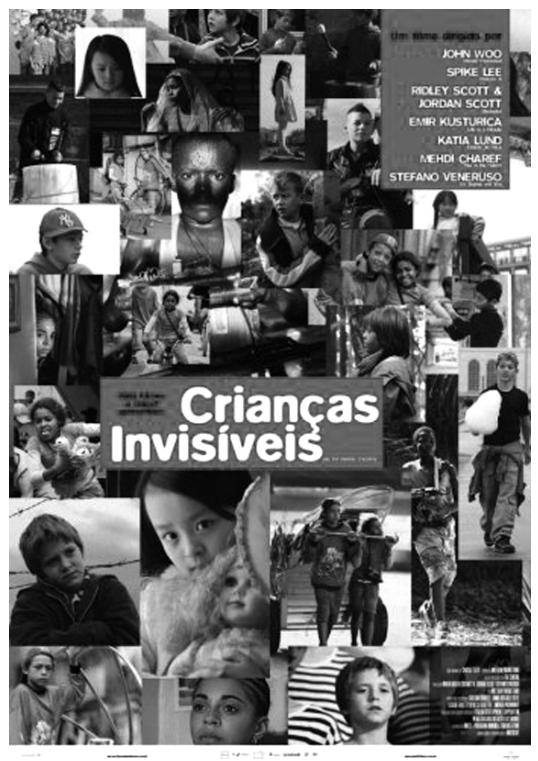
personagens infantis que lidam com duras e sofridas realidades. Todos os diretores trabalharam de graça e parte da renda do filme foi destinada ao Unicef e ao Programa Mundial contra a Fome.

Seguindo um pouco a proposta de Alain Brigand, que convidou onze diretores para contar onze histórias sobre o onze de setembro de 2001, a produtora italiana Chiara Tilesi, sugeriu a oito cineastas que mostrassem suas versões sobre a inclusão social das crianças no mundo. Os diretores convidados tiveram total liberdade para escolher temas e abordagens.

Mehdi Charef conta a histó12 ria de um grupo de crianças em algum lugar da África não especificado; todas guerrilheiras. Tanza é um dos meninos-soldados e tem 12 anos. Emir Kusturica narra, em Blue Gypsy, a realidade de um reformatório em Sérvia e Montenegro. O personagem principal é Urus, que não tem certeza se quer sair do reformatório e voltar a viver com um pai alcoólatra, explorador de crianças. Em Jesus Children of América, Spike Lee mostra a vida de Blanca, uma menina de Nova York, filha de pais drogados e portadores de HIV.

Kátia Lund retrata as desventuras de Bilu \& João na cidade de São Paulo, duas crianças que passam o dia catando coisas, vendendo e revendendo para comprar tijolos

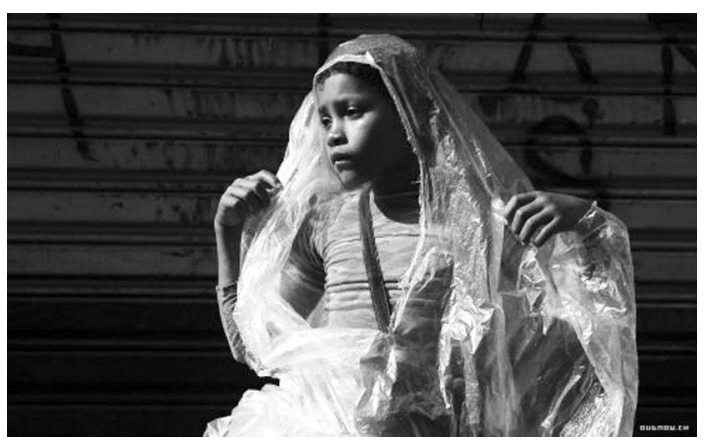


para a casa do irmão que está sendo construída. Uma história reflexiva sobre um fotógrafo de guerra é o mote de Jordan e Ridley Scott. O personagem Jonatham, em determinado momento, questiona seu trabalho e pensa em desistir, pois acredita não estar ajudando as pessoas retratadas. Sua companheira argumenta em favor do ofício. Ele deixa a casa, no frio, e vê duas crianças na mata. Segue-as e, quando nada para encontrá-las em um barco, torna-se criança. Os três brincam na mata e chegam a uma trincheira, no meio da guerra. Após o fim do tiroteio, retornam. O protagonista volta a ficar adulto.

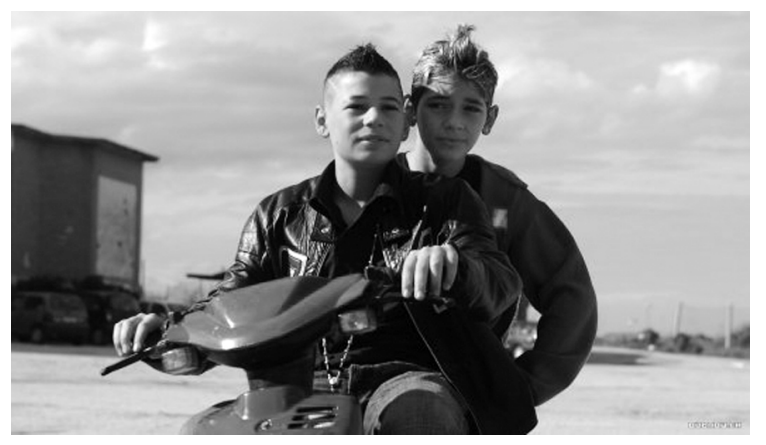

Stefano Veneruso nos traz Ciro, um menino que furta um rolex de certo executivo num cruzamento. Inquilino de sua própria casa, o garoto tem de pagar para viver nela. Quando, juntamente com um colega, vão vender o relógio, outro aspecto da violência contra a criança é denunciado: a pedofilia. Embora Ciro não permita ser tocado fisicamente, tem consciência de sua condição e prefere naquele momento voltar a ser uma criança brincando num parque de diversões vazio.

John Woo, em seu Song Son \& Little Cat, relata os conflitos de duas meninas: uma rica, que sofre pela separação dos pais, e uma pobre, encontrada por um velhinho na lata de lixo, que sonha um dia poder freqüentar a escola.

\section{SOBRE FILMES E DIRETORES. HISTÓRIAS QUE PODEM INTERESSAR}

A história de Camelos Também Choram começou na Escola de Cinema em Munique ${ }^{4}$, na Alemanha. Byambasuren Davaa contou ao colega de classe Luigi Falorni a tradição dos nômades de sua terra natal. Quando um camelo recém-nascido é repelido pela mãe, um ritual deve ser realizado a fim de que o filhote não morra. Um músico, então, é chamado para, com sua música, emocionar a mãe que rejeitou a cria. Os dois jovens cineastas resolvem fazer dessa história o tema de trabalho de sua conclusão de curso e partem para o deserto de Gobi, com a intenção de acompanhar a temporada de

4. <http://enquadramento blogspot.com/2005/07/ camelos-tambm-choram. html>.

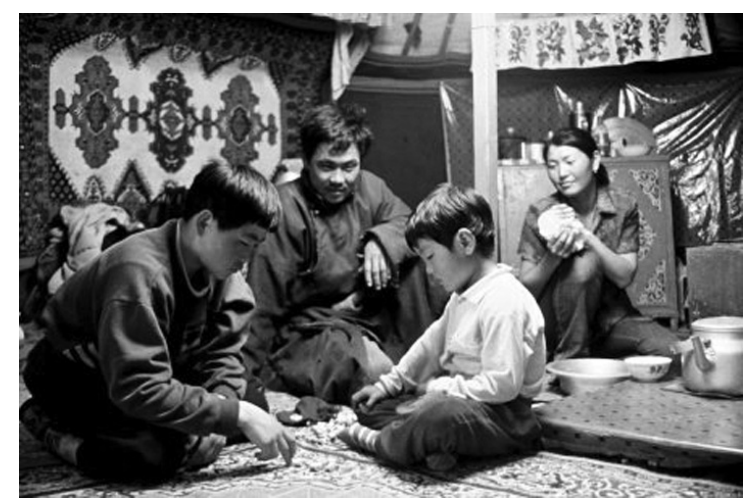


de nômades de quatro gerações que vive sob uma mesma tenda, a qual se dispõe a participar das filmagens.

O filme foi gravado sem atores e diálogos ensaiados, uma vez que as situações iam organizando-se de acordo com a rotina dos membros da família. O grande achado foi a gravação inesperada do nascimento de um camelo albino; achado porque, a princípio, seria um filme sobre famílias nômades.

Especificamente em relação ao cinema produzido por Davaa e

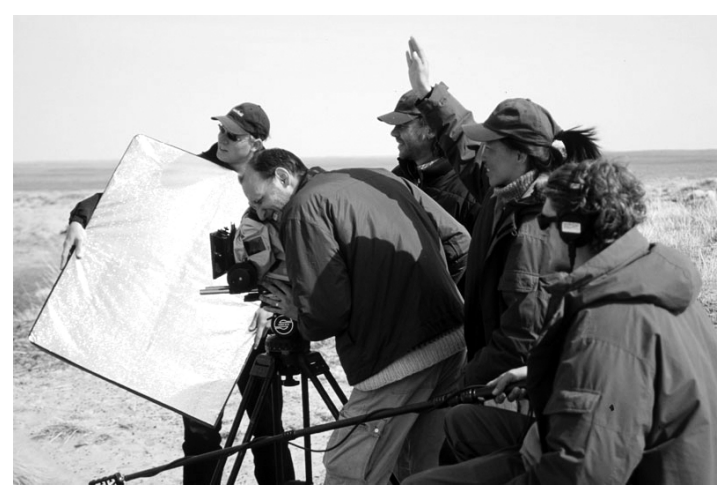
Falorni, os analistas comparam a experiência dos jovens cineastas ao primeiro documentário longa-metragem da história: Nanook, o Esquimó (1922), de Robert Flatherly, que acompanhou durante um ano a vida de uma família de esquimós no Ártico.

Pelo fato de os filmes terem sido escolhidos por suas diferentes narrativas e o exercício proposto ter como um dos objetivos a descoberta do que está além do visível, acredito ser interessante sabermos um pouco de histórias distantes das narrativas cinematográficas.

Crianças Invisíveis foi idealizado pela italiana Chiara Tilesi, com produção de Maria Grazia Cucinotta e Stefano Veneruso. Chiara contou com apoio do governo italiano e posteriormente do Unicef e da WFP (World Food Program). Segundo a produtora, o objetivo é trazer o tema das crianças negligenciadas para ciência e consciência do público e, no mínimo, torná-las mais visíveis. Stefano Veneruso foi diretor-assistente de Martin Scorcese em Gangues de NY e é sobrinho de Massimo Troisi, de $O$ Carteiro e o Poeta.

\section{CAMELOS E CRIANÇAS. ESTUDO E PERCEPÇÃO DO VISÍVEL}

Apesar de sabermos que o óbvio não é tão óbvio porque esconde essências só perceptíveis por meio de um refinado exercício do olhar, não podemos negar o lado visível da realidade histórica e social, como também as diferenças entre os filmes escolhidos. São projetos artísticos com objetivos próprios. Falamos de camelos e de crianças em regiões, culturas e sociedades específicas. Falamos de documentário e curtas-metragens.

No documentário de Davaa e Falorni, podemos trabalhar muitos temas em sala de aula, e o primeiro deles é a lenda; ou as diferentes lendas dos países e dos animais distantes de nossa realidade. Isso porque o documentário começa com o ancião contando a lenda dos camelos. Explica que originalmente esses animais tinham chifres, que emprestaram aos veados. No entanto, estes desapareceram no infinito e, até hoje, os camelos guardam esse olhar para 
o horizonte, esperando o dia em que terão de volta os seus ornamentos. Assim, tornaramse melancólicos e contemplativos; melancolia que pode ser percebida pela fotografia e câmera de Luigi Falorni, quando enquadra e repousa a câmera sobre os olhos dos camelos direcionados para o horizonte. A despeito da lenda,

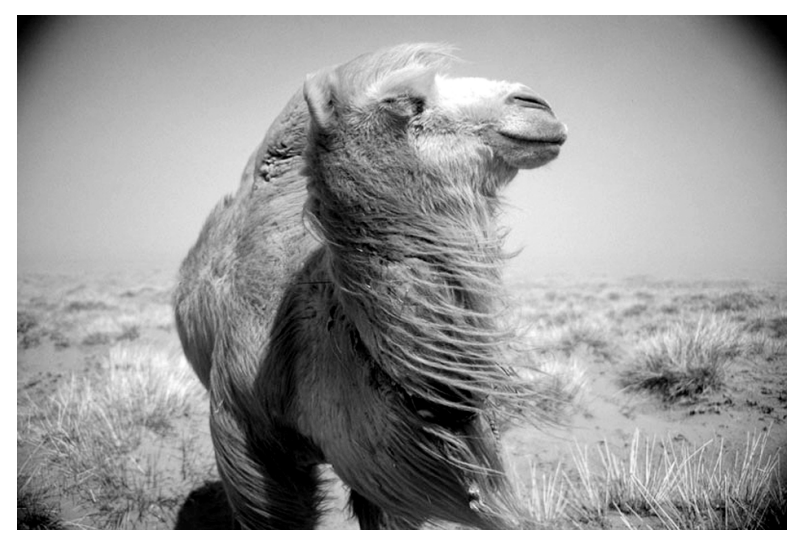
é possível desenvolver um estudo sobre esses animais desajeitados, exóticos e aparentemente pouco cinematográficos.

Um outro aspecto que pode ser abordado é o dos desertos existentes no planeta, suas histórias e características. Como o mar, o deserto também fascina. E, ao contrário do que imaginamos, possue histórias. Está, como todas as coisas vivas, em movimento, e o deserto de Gobi é exemplo disso. Já que a geografia é o ponto de pesquisa, vale trabalhar essa região que, de acordo com estudos mitológicos, foi um dos berços da raça ariana.

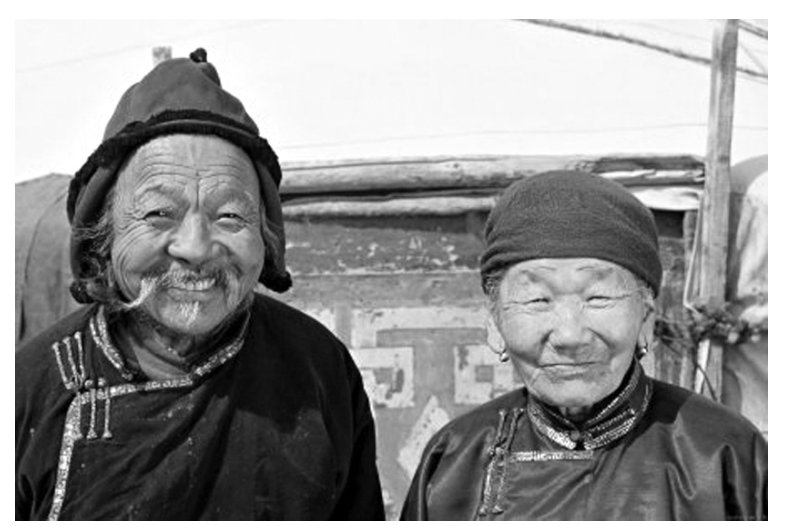

Do ponto de vista histórico e antropológico, podemos aprofundar nossos conhecimentos sobre os povos nômades de outrora e os atuais. Nômades do deserto ou nômades de outros lugares. Nômades rurais e urbanos. Aspectos da cultura nômade e, em especial, da cultura das populações nômades da Mongólia que, apesar de resistir, a cada ano desaparece um pouco. Especificamente, os efeitos do mundo contemporâneo sobre as populações e suas tradições.

Quanto aos curtas-metragens de Crianças Invisíveis, a poesia é seca, não faz concessões. Ao contrário, a realidade está escancarada a nossa frente. Em cada um dos países apresentados, os problemas, se não são os mesmos nem aparecem com a mesma intensidade ou gravidade, revelam-se parecidos, próximos e não nos causam estranheza. Desigualdades sociais, violência infantil, guerras, doenças, preconceitos, abandonos, explorações. De tanto saber, ver e conviver com tudo isso, perdemos a capacidade de sentir e enxergar.

Existem também outros lugares e personagens que nos são pouco conhecidos, como, por exemplo, as histórias de Tanza e Urus. São crianças da África, de Sérvia e Montenegro, povos distantes, descartados no contexto do mundo globalizado e minimizados nas páginas dos livros didáticos, na mídia impressa, nos noticiários da TV. 
Diante disso, vale investirmos na pesquisa das populações que pouco conhecemos, em suas regiões, histórias e lutas étnicas e religiosas. Mais especificamente a África Negra, palco de lutas internas e externas. Muitas guerras civis ou conflitos entre tribos são provocados por povos e grupos detentores do grande capital.

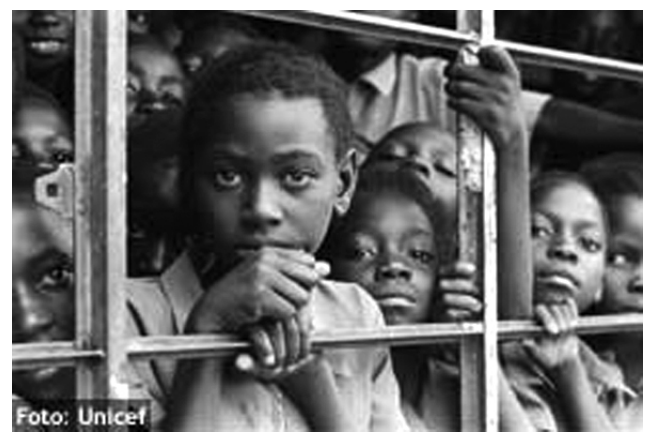

Quanto aos povos mais conhecidos, como os norte-americanos, os ingleses e os italianos, as reflexões e os estudos poderiam partir da temática apresentada em cada um dos curtas-metragens e buscar o lado oculto da história, o temário que está do outro lado, ou seja, a realidade que não sai nas páginas dos jornais nem nas telas de TV e cinema.

\section{EXCLUÍDOS E INVISÍVEIS. PERCEPÇÃO E ESTUDO DO INVISÍVEL}

Se retomarmos as sinopses de cada um dos filmes sugeridos, perceberemos que tanto Camelos Também Choram como Crianças Invisíveis - embora tenham por objetivo mostrar ou colocar em discussão a temática da exclusão e da inclusão, seja a de camelos, seja a de crianças rejeitadas - trazem-nos experiências que ressaltam "a existência de uma parte da vida social que escapa à ordem da racionalidade instrumental ou a redução da vida à simples lógica da dominação", como nos coloca Michel Maffesoli.

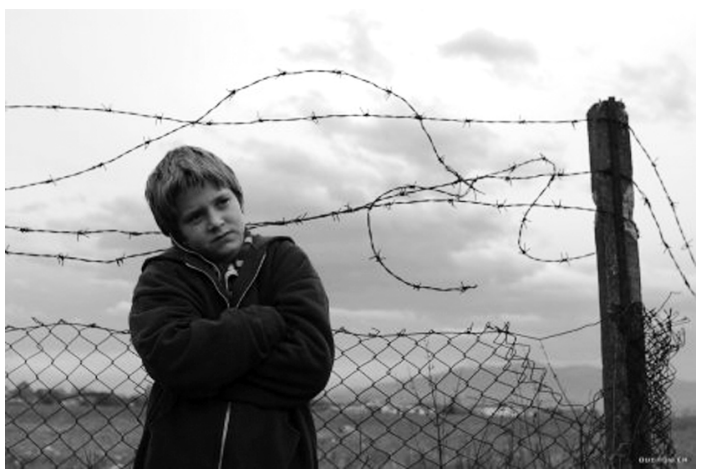

E como a segunda proposta de exercícios com os filmes selecionados é olhar para além dos fatos e das realidades apresentadas, gostaria de propor uma leitura do invisível, melhor dizendo, o que pode ser percebido nos gestos, nos ritos e nas experiências que delimitam outros espaços de liberdade. Como o querer-viver do camelo albino, que encontra no ritual da música a sensibilidade ne-

cessária para que sua mãe o aceite. Em Bilu \& João, a amizade e a solidariedade que tornam mais leve a luta e a pobreza enfrentadas diariamente. Em meio ao trabalho nas ruas e ao cotidiano na favela, o desejo de comer batatas fritas é pretexto para amenizar o dia seguinte. Para Urus, entre a vida no reformatório e a de ladrão mirim nas ruas de alguma cidade de Sérvia e Montenegro, ele sonha com a normalidade de ter uma profissão: a de barbeiro.

Em Jesus, Children of America, podemos perceber a inversão do estereótipo: Blanca não é só mais uma criança negra nascida de pais drogados, mas a filha

5. MAFFESOLI, op. cit., p. 83. 
querida de pais drogados e portadores de HIV. A doença não é apenas deles, mas de uma sociedade e de seu país. Little Cat mostra-nos dois caminhos da educação: o dos sentimentos e o da escola formal. Apesar de abandonada em uma lata de lixo, Little Cat aprendeu o significado de ser uma pessoa e de querer ter uma formação. Tanza representa a África duplamente esquartejada: a do século XIX, quando a Europa civilizada dividiu suas terras e seus povos, e a dos dias atuais, em que os detentores da tecnologia e do grande capital vêm transformando sua gente em mercadorias descartáveis no contexto globalizado. Vidas desperdiçadas, meninos-soldados que, a cada baixa em emboscadas ou confrontos diretos, são simplesmente repostos. Dos sonhos, o estilingue e os lápis escondidos na parede da casa destruída pela guerra. Na guerra, que não é sua, os olhos e os ouvidos atentos no grupo de crianças que brinca na aldeia que será destruída, e a liberdade de responder à lição de casa que poderia ser sua, de tirar o tênis sob a carteira escolar e repousar a cabeça sobre a bomba.

Para finalizar, Ciro, o menor infrator, leva-nos ao parque de diversões. Vazio de crianças, põe para funcionar uma roda de bichinhos. Não precisava, bastava a seqüência da dança de suas mãos e de seu corpo projetada na parede e em direção à porta de sua casa, quando ouve a voz de sua mãe que o renega. Nas imagens desenhadas na parede está a mágica de Ciro e do cinema.

Resumo: A proposta desta videografia é apresentar dois filmes de naturezas diferentes, mas que possuem aspectos comuns: a exclusão e a reflexão sobre a idéia de invisível, ou o que se pode tornar visível: Camelos Também Choram é um documentário narrativo que retrata a vida dos nômades do deserto de Gobi na Mongólia; e Crianças Invisíveis são sete curtas de diversos países que têm como temática a dura realidade de personagens infantis. A autora propõe para este número da revista um duplo exercício do olhar: discutir o que está dado a ser visto e o que pode ser descoberto.

Palavras-chave: exclusão, inclusão, visibilidade, infância, cinema.
Abstract: This videography presents motion pictures of distinct natures, but that have two aspects in common: the exclusion and the reflection about the idea of invisible, or what can become visible: The Story of the Weeping Camel is a documentary that shows the life of nomads in Mongolia's Gobi desert; and All the Invisible Children are seven short films of various countries that have as theme the hard realities children characters. The author proposes an exercise in interpretation: the discussion what is offered to be seen and what can be found.

Keywords: exclusion, inclusion, visibility, childhood, cinema. 